\title{
Development of screening technique for artificial creation of false smut in rice
}

\author{
Yesmin Kaur $^{1 *}$, J. S. Lore ${ }^{2}$ and P. P. S. Pannu ${ }^{1}$ \\ ${ }^{1}$ Department of Plant Pathology, Punjab Agricultural University, Ludhiana-141004 (Punjab), INDIA \\ ${ }^{2}$ Department of Plant Breeding and Genetics, Punjab Agricultural University, Ludhiana-141004 (Punjab), INDIA \\ *Corresponding author. E-mail: yesminkaur@gmail.com
}

Received: August 31, 2017; Revised received: September 27, 2017; Accepted: January 31, 2018

\begin{abstract}
False smut (Ustilaginoidea virens (Cooke) Takahashi) of rice is an emerging disease and a potential threat to rice growers in different countries due to reduction in yield, quality and production of mycotoxins. Development and cultivation of resistant varieties is desirable approach for its management. Different inoculation techniques viz. spray inoculation, syringe inoculation and dusting method were evaluated for creating artificial epiphytotic conditions in susceptible variety PR116 under natural as well as artificially provided humidity conditions. Spray inoculation method produced more number of smut balls per plant (3.21) and per cent infected panicles (33.44\%) followed by syringe inoculation ( 2.00 and $26.57 \%$, respectively) and dusting method ( 0.33 and $6.67 \%$, respectively). However, syringe inoculation method produced more spikelet sterility $(14.82 \%)$ in rice panicles. More disease occurrence was reported in plants provided with artificial humidity after inoculations (51.12\% infected panicles) than the plants grown under natural conditions (13.33\% infected panicles). Late transplanted crop developed higher disease severity (18.17\% infected panicles and 3.34 smut balls/plant) which might be attributed by slight decrease in temperature and increase in relative humidity conditions (up to $88 \% \mathrm{RH}$ ) at time of infection from boot to early flowering stage of the rice crop.
\end{abstract}

Keywords: Artificial humidity, False smut, Inoculation methods, Rice

\section{INTRODUCTION}

False smut of rice, caused by Ustilaginoidea virens (Cooke) Takahashi, is becoming a serious concern in commercial rice production. It has become the most devastating rice grain disease in different rice producing countries chiefly due to large scale expansion of high yielding varieties, use of chemical fertilizers and climate change. Disease becomes visible when smut balls develop in spikelets instead of normal grain production which leads to yield reduction. Smut balls are initially covered by thin epidermal membrane which later ruptures to release yellow coloured chlamydospores which ultimately turns olive green to blackish in colour with maturity of the crop. The disease not only causes quantitative yield reduction but also affects the quality of the produce as the pathogen produces ustiloxins, the mycotoxins on the diseased tissue and the antimitotic cyclic peptides from its chlamydospores which are poisonous to both humans and animals (Nakamura et al., 1994).

Although the disease can be managed to some extent by spraying different fungicides like propiconazole and trifloxistrobin+tebuconazole (Raji et al., 2016) and cultural management strategies including manipulation of sowing times (Nessa et al., 2015) but identification of resistant sources is more desirable approach for its management. As the successful infection rate of artificial inoculation is very low, it is difficult to create the epiphytotic artificially under field conditions which is also a limiting factor for screening of rice germplasm. Therefore, a study was carried out with the objective to standardize the innovative screening technique for artificial creation of the disease under field as well as under greenhouse conditions.

\section{MATERIALS AND METHODS}

Seeds of local susceptible variety, PR116 were collected from Department of Plant Breeding and Genetics and sown in two different dates at Experimental area of Department of Plant Breeding and Genetics, Punjab Agricultural University, Ludhiana. The experiments were conducted in Completely Randomized Block Design (CRD) and Randomized Block Design (RBD) and data was evaluated using factorial ANOVA test.

Under greenhouse conditions: One month old nursery was transplanted in pots and placed under greenhouse conditions at temperature $27 \pm 2^{\circ} \mathrm{C}$ in Completely Randomized Block Design (CRD) with three replications for each treatment. Humidity was maintained artificially at $90 \%$ by using humidifiers in the greenhouse. Spore suspension was prepared in distilled wa- 
ter from the fungal pathogen cultured on potato sucrose broth (PSB) medium. The suspension was inoculated in three different ways. Spray inoculation of the spore suspension at early flowering stage using hand sprayer. Dusting of dry spore mass on newly emerged panicles at early flowering stage. Syringe inoculation of spore suspension in to the boot of developing panicle in two volumes viz. 1 and $2 \mathrm{ml}$ using sterilized dermal syringes (Ashizawa et al., 2011). Un-inoculated pot plants were kept as check.

\section{Under field conditions}

Standardization of different inoculation methods under natural as well as artificially provided humidity conditions: One month old nursery was transplanted in field in randomized block design (RBD) with three replications for each treatment in the plot size of one sq. meters having 25 plants with $20 \times 20$ $\mathrm{cm}$ spacing. A perfo spray system was installed in the field for maintaining artificial humidity after inoculations by spraying ordinary water during day time. Spore suspension was prepared in distilled water from the fungal pathogen cultured on PSB medium and the suspension was inoculated by spray inoculation, dusting and syringe inoculation. A whole plot of 25 plants in each replication was kept as check and was not inoculated.

Validation of different inoculation methods in different transplanting dates of rice: One month old nursery was transplanted in field in two different dates viz. $15^{\text {th }}$ June and $1^{\text {st }}$ July, 2013 in randomized block design (RBD) with three replications for each treatment. Spore suspension was prepared in distilled water from the fungal pathogen and the suspension was inoculated by spray inoculation, dusting and syringe inoculation. A whole plot was not inoculated and was kept as check.

Comparison of type of inoculum used for inoculations: The crop plots, at early flowering stage, were sprayed with spore suspension of fresh inoculum taken from the early sown infected crop and the cultured inoculum prepared in vitro in PSB medium. The treatments were kept in three replications and each plot was left un-inoculated and was kept as check.

Disease data on various disease variables such as percentage of infected panicles, smut balls produced per plant, smut balls produced per panicle and percentage sterility of spikelets was recorded from each plot.

\section{RESULTS AND DISCUSSION}

Data presented in Table 1 reveals that significantly higher percentage of infected panicles $(33.44 \%)$ was produced in spray inoculation method followed by syringe inoculation method of $1 \mathrm{ml}$ of spore suspension $(26.57 \%)$ and $2 \mathrm{ml}$ of spore suspension (22.46\%) at 5 per cent level of significance. The infected panicles produced by dusting method $(6.67 \%)$ were signifi-

Table 1. Comparative performance of different inoculation methods for creation of false smut disease in rice plants by inoculation of spore suspension under greenhouse conditions.

\begin{tabular}{llllll}
\hline Inoculation method & $\begin{array}{l}\text { Infected pan- } \\
\text { icles (\%) }\end{array}$ & $\begin{array}{l}\text { Smut Balls/ } \\
\text { Plant }\end{array}$ & $\begin{array}{l}\text { Smut Balls/ } \\
\text { Panicle }\end{array}$ & Sterility (\%) & $\begin{array}{l}\text { Increased spikelet steril- } \\
\text { ity over check (\%) }\end{array}$ \\
\hline Spray Inoculation & $33.44(5.86)$ & $3.21(2.05)$ & $0.48(1.21)$ & $13.02(3.60)$ & 14.81 \\
Dusting & $6.67(2.76)$ & $0.33(1.15)$ & $0.07(1.03)$ & $10.67(3.26)$ & - \\
Syringe Inoculation @ 1ml & $26.57(5.24)$ & $2.00(1.71)$ & $0.40(1.18)$ & $13.24(3.63)$ & 16.75 \\
Syringe Inoculation @ 2ml $2 \mathrm{ml}$ & $22.46(4.84)$ & $1.67(1.63)$ & $0.33(1.15)$ & $14.82(3.84)$ & 30.69 \\
Un-inoculated Check & $20.06(4.50)$ & $1.63(1.62)$ & $0.30(1.14)$ & $11.34(3.36)$ & - \\
CD (p=0.05) & 0.79 & 0.12 & 0.02 & 0.10 & - \\
\hline
\end{tabular}

*Values in parenthesis are square-root transformed values

Table 2. Comparative performance of different inoculation methods for creation of epiphytotic of false smut disease in rice field under natural as well as artificially provided humidity conditions

\begin{tabular}{|c|c|c|c|c|c|c|}
\hline Conditions & Inoculation method & $\begin{array}{l}\text { Infected pani- } \\
\text { cles (\%) }\end{array}$ & $\begin{array}{l}\text { Smut Balls/ } \\
\text { Plant }\end{array}$ & $\begin{array}{l}\text { Smut Balls/ } \\
\text { Panicle }\end{array}$ & $\begin{array}{l}\text { Sterility } \\
(\%)\end{array}$ & $\begin{array}{l}\text { Increased spikelet } \\
\text { sterility over } \operatorname{check}(\%)\end{array}$ \\
\hline \multirow{5}{*}{$\begin{array}{l}\text { Under natural } \\
\text { condition }\end{array}$} & Spray Inoculation & $13.33(3.65)$ & $3.59(1.87)$ & $0.24(0.48)$ & $12.72(3.57)$ & 2.99 \\
\hline & Dusting & $10.48(3.21)$ & $0.66(0.80)$ & $0.13(0.36)$ & $10.74(3.27)$ & - \\
\hline & Syringe Inoculation@1ml & $11.25(3.32)$ & $1.33(1.15)$ & $0.22(0.47)$ & $12.89(3.58)$ & 4.37 \\
\hline & Syringe Inoculation @2ml & $11.20(3.33)$ & $1.23(1.10)$ & $0.13(0.36)$ & $13.46(3.67)$ & 8.99 \\
\hline & Un-inoculated Check & $7.34(2.65)$ & $0.53(0.73)$ & $0.06(0.24)$ & $12.35(3.51)$ & - \\
\hline \multirow{5}{*}{$\begin{array}{l}\text { Under artificially } \\
\text { provided humidi- } \\
\text { ty condition }\end{array}$} & Spray Inoculation & $51.12(7.15)$ & $7.33(2.69)$ & $1.46(1.21)$ & $13.67(3.69)$ & 11.41 \\
\hline & Dusting & $18.38(4.28)$ & $1.33(1.08)$ & $0.33(0.57)$ & $11.65(3.41)$ & - \\
\hline & Syringe Inoculation@1ml & $33.33(5.77)$ & $5.35(2.31)$ & $0.64(0.79)$ & $14.88(3.86)$ & 21.27 \\
\hline & Syringe Inoculation@2ml & $27.39(5.17)$ & $3.92(1.97)$ & $0.46(0.66)$ & $16.73(4.09)$ & 36.35 \\
\hline & Un-inoculated Check & $21.47(4.63)$ & $3.33(1.82)$ & $0.39(0.62)$ & $12.27(3.51)$ & - \\
\hline \multirow{3}{*}{$\mathrm{CD}(\mathrm{p}=0.05)$} & lons & 0.3739 & 0.2057 & 0.0781 & 0.1057 & - \\
\hline & ulation methods & 0.5912 & 0.3253 & 0.1235 & 0.1672 & - \\
\hline & $\times$ Inoculation methods & 0.836 & NS & 0.1747 & NS & - \\
\hline
\end{tabular}

*Values in parenthesis are square-root transformed values 
Table 3. Comparative performance of different inoculation methods for creating artificial epiphytotic of false smut disease in timely and late transplanted rice crop.

\begin{tabular}{|c|c|c|c|c|}
\hline Date of transplanting & Inoculation method & Infected panicles (\%) & Smut Balls/ Plant & Smut Balls/ Panicle \\
\hline \multirow{5}{*}{$\begin{array}{l}\text { Timely transplanted } \\
\text { crop i.e. } 15 \text { June }\end{array}$} & Spray Inoculation & $11.11(3.33)$ & $0.89(0.94)$ & $0.18(0.41)$ \\
\hline & Dusting & $6.49(2.54)$ & $0.55(0.74)$ & $0.08(0.27)$ \\
\hline & Syringe Inoculation@1ml & $11.11(3.29)$ & $0.66(0.81)$ & $0.12(0.33)$ \\
\hline & Syringe Inoculation@2ml & $6.66(2.56)$ & $0.63(0.78)$ & $0.09(0.29)$ \\
\hline & Un-inoculated Check & $3.39(1.84)$ & $0.27(0.51)$ & $0.05(0.22)$ \\
\hline \multirow{5}{*}{$\begin{array}{l}\text { Late transplanted crop } \\
\text { i.e. } 1 \text { July }\end{array}$} & Spray Inoculation & $18.17(4.25)$ & $3.34(1.82)$ & $0.49(0.69)$ \\
\hline & Dusting & $10.42(3.22)$ & $1.33(1.15)$ & $0.17(0.41)$ \\
\hline & Syringe Inoculation@1ml & $15.51(3.93)$ & $2.85(1.66)$ & $0.33(0.56)$ \\
\hline & Syringe Inoculation @2ml & $15.47(3.92)$ & $1.33(1.15)$ & $0.22(0.46)$ \\
\hline & Un-inoculated Check & $7.15(2.62)$ & $0.87(0.92)$ & $0.06(0.24)$ \\
\hline \multirow{3}{*}{\multicolumn{2}{|c|}{$\begin{array}{ll}\mathrm{CD}(\mathrm{p}=0.05) & \text { Conditions } \\
& \text { Inoculation methods } \\
\text { Conditions } \times \text { Inoculation methods }\end{array}$}} & 0.2252 & 0.1339 & 0.0781 \\
\hline & & 0.3561 & 0.2117 & 0.1236 \\
\hline & & NS & NS & NS \\
\hline
\end{tabular}

*Values in parenthesis are square-root transformed values

Table 4. Weather factors prevailing at the time of flowering of the rice crop.

\begin{tabular}{|c|c|c|c|c|c|c|c|c|}
\hline \multirow{2}{*}{ Week } & \multicolumn{3}{|c|}{ Temperature $\left({ }^{\circ} \mathrm{C}\right)$} & \multicolumn{3}{|c|}{ Relative Humidity (\%) } & \multirow{2}{*}{$\begin{array}{l}\text { Rainfall } \\
(\mathrm{mm})\end{array}$} & \multirow{2}{*}{$\begin{array}{l}\text { Sunshine } \\
\text { Hours }\end{array}$} \\
\hline & Maximum & Minimum & Mean & Maximum & Minimum & Mean & & \\
\hline 33 & 31.2 & 25.6 & 28.4 & 91 & 75 & 83.0 & 130.6 & 4.2 \\
\hline 34 & 34.8 & 26.8 & 30.8 & 90 & 63 & 76.5 & 4.5 & 6.5 \\
\hline 35 & 34.4 & 26.4 & 30.4 & 86 & 59 & 72.5 & 3.2 & 9.2 \\
\hline 36 & 34.0 & 25.6 & 29.8 & 84 & 68 & 76 & 12.2 & 7.9 \\
\hline 37 & 34.1 & 24.4 & 29.3 & 85 & 57 & 71 & 0.0 & 8.7 \\
\hline 38 & 33.6 & 22.6 & 28.1 & 89 & 55 & 72 & 0.0 & 8.7 \\
\hline 39 & 33.0 & 23.5 & 28.3 & 88 & 62 & 75 & 25.3 & 6.7 \\
\hline 40 & 32.1 & 24.0 & 28.1 & 89 & 63 & 76 & 22.4 & 4.8 \\
\hline
\end{tabular}

cantly lesser at 5 per cent level of significance than those produced in plants kept as check (20.06\%). Number of smut balls produced per plant and per panicle were also significantly maximum in spray inoculation method (3.21 and 0.48 , respectively) followed by syringe inoculation of $1 \mathrm{ml}$ of spore suspension $(2.00$ and 0.40 , respectively) and $2 \mathrm{ml}$ of spore suspension (1.67 and 0.33 , respectively). While dusting of dry spores produced significantly lesser number of smut balls per plant and per panicle $(0.33$ and 0.07 , respectively) at 5 per cent level of significance. However, syringe inoculation of $2 \mathrm{ml}$ spore suspension produced significantly higher per cent of spikelet sterility in rice

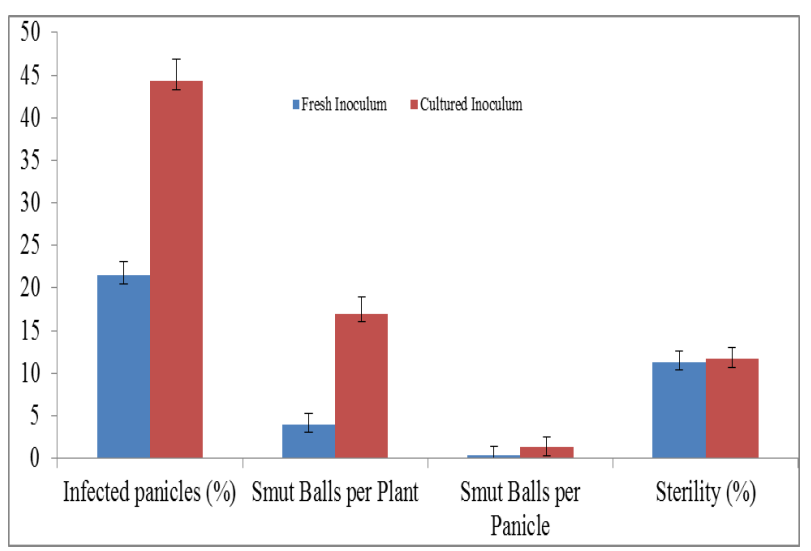

Fig. 1. Comparison of different types of inoculum used for inoculations of rice plants. panicles (30.69\% over the check). While no significant difference was observed in spikelet sterility produced by spray inoculation and syringe inoculation of $1 \mathrm{ml}$ spore suspension (14.81 and $16.75 \%$ over the check, respectively).

Table 2 represents the data of different inoculation methods under natural as well as artificially provided humidity conditions. Significantly higher numbers of disease variables were produced in plants in which artificial humidity was provided after inoculations as compared to those which were grown under natural conditions. In plants provided with artificial humidity after inoculations, maximum percentage of infected panicles were produced in spray inoculation $(51.12 \%)$ followed by syringe inoculation of $1 \mathrm{ml}$ spore suspension $(33.33 \%)$ and $2 \mathrm{ml}$ of spore suspension $(27.39 \%)$ at 5 per cent level of significance. Similarly, in plants grown under natural conditions, spray inoculation method produced significantly higher per cent of infected panicles $(13.33 \%)$ followed by syringe inoculation of $1 \mathrm{ml}$ spore suspension $(11.25 \%)$ and $2 \mathrm{ml}$ of spore suspension (11.20\%). While the dusting method produced significantly lesser per cent of infected panicles in artificially provided humidity conditions as well as in natural conditions (18.38 and $10.48 \%$, respectively) at 5 per cent level of significance. Likewise, number of smut balls produced per plant and per panicle was also significantly higher in plants provided with artificial humidity after inoculations. Spray inoculation 
produced significantly higher number of smut balls per plant (7.33 in artificially provided humidity and 3.59 in natural conditions) and per panicle (1.46 in artificially provided humidity and 0.24 in natural conditions) followed by syringe inoculation of $1 \mathrm{ml}$ of spore suspension ( 5.35 smut balls per plant, 1.33 smut balls per panicle in artificially provided humidity and 0.64 smut balls per plant, 0.22 smut balls per panicle in natural conditions), $2 \mathrm{ml}$ of spore suspension (3.92 smut balls per plant, 1.23 smut balls per panicle in artificially provided humidity and 0.46 smut balls per plant, 0.13 smut balls per panicle in natural conditions) and dusting method (1.33 smut balls per plant, 0.66 smut balls per panicle in artificially provided humidity and 0.33 smut balls per plant, 0.13 smut balls per panicle in natural conditions) (Table 2). Spikelet sterility along with the disease produced in rice panicles was significantly more under artificially provided humidity conditions than under natural conditions. Syringe inoculation of $2 \mathrm{ml}$ spore suspension produced higher spikelet sterility in both artificial humidity as well as natural conditions (36.35 and $8.99 \%$ over the check, respectively) followed by syringe inoculation of $1 \mathrm{ml}$ spore suspension $(21.27$ and $4.37 \%$ over the check, respectively) and spray inoculation (11.41 and 2.99\% over the check, respectively).

Figure 1 reveals that higher number of disease variables was produced by spraying spore suspension of cultured inoculum than fresh inoculum taken from early sown infected crop. Cultured and fresh inoculum produced 44.31 and 21.47 per cent infected panicles, respectively. Number of smut balls produced per plant and per panicle was 16.99 and 1.35 , respectively in cultured inoculum and 3.99 and 0.39 , respectively in fresh inoculum. The spikelet sterility was significantly at par in cultured as well as fresh inoculum (11.65 and $11.33 \%$, respectively).

Table 3 represents the data of various disease variables produced by different inoculation methods under timely (i.e. on $15^{\text {th }}$ June) and late transplanted crop (i.e. $1^{\text {st }}$ July). Late transplanted rice crop developed higher disease variables as compared to timely transplanted crop. Various disease variables like percentage of infected panicles, number of smut balls per plant and per panicle produced by spray inoculation was significantly more in late transplanted crop $(18.17 \%, 3.34$ and 0.49 , respectively) as compared to timely transplanted crop $(1.11 \%, 0.89$ and 0.18 , respectively). This was followed by syringe inoculation of $1 \mathrm{ml}$ of spore suspension $(15.51 \%, 2.85$ and 0.33 , respectively in late transplanted conditions and $11.11 \%, 0.66$ and 0.12 , respectively in timely transplanted conditions) and $2 \mathrm{ml}$ of spore suspension $(15.47 \%, 1.33$ and 0.22 , respectively in late transplanted conditions and $6.66 \%, 0.63$ and 0.09 , respectively in timely transplanted conditions) at $5 \%$ level of significance (Table 3). Significantly lesser number of smut balls per plant and per panicle was produced by dusting method in late $(1.33$ and 0.17 , respectively) and timely transplanted crop ( 0.55 and 0.08 , respectively).

Table 4 represents data of various weather conditions prevailing at the time of 50 per cent flowering of the crop. Fifty per cent of the timely transplanted and late transplanted crop flowered in $37^{\text {th }}$ and $39^{\text {th }}$ week, respectively. Although the mean temperature of $37^{\text {th }}$ week $\left(29.3^{\circ} \mathrm{C}\right)$ was $1^{\circ} \mathrm{C}$ more than that of $39^{\text {th }}$ week $\left(28.3^{\circ} \mathrm{C}\right)$ but the maximum relative humidity was $85 \%$ in $37^{\text {th }}$ week and $88 \%$ in $39^{\text {th }}$ week) in the latter case. Likewise, total rainfall in $39^{\text {th }}$ week was $25.3 \mathrm{~mm}$ while it was negligible in $37^{\text {th }}$ week. On the contrary, there were 8.7 sunshine hours in $37^{\text {th }}$ week while 6.7 hours in $39^{\text {th }}$ week. More relative humidity and rainfall along with lesser temperature and sunshine hours might have resulted in higher disease production in late transplanted crop.

Present investigations revealed that maximum disease variables (i.e. percent infected panicles, number of smut balls per plant and smut balls per panicle) were produced by spray inoculation method $(51.12 \%, 7.33$ and 1.46 , respectively) followed by syringe inoculation method $(33.33 \%, 5.35$ and 0.64 , respectively) and dusting $(18.38 \%, 1.33$ and 0.33 , respectively) under field conditions. Similarly, Pannu et al. (2010) reported that more disease incidence $(80.65$ and $86.85 \%$ during 2005 and 2006) was recorded in rice plants inoculated by spraying method and provided with artificial humidity after inoculations as compared with the plants grown under natural conditions (5.65 and $10.30 \%$ during 2005 and 2006). Singh (2009) produced similar results in which the disease incidence and disease severity was maximum in rice plants which were spray inoculated followed by syringe inoculation and dropper inoculation method. Wang et al. (2008) also studied the inoculation methods for confirming the pathogenecity of Ustilaginoidea albicans, the cause of white false smut of rice in China and observed that inoculations by spraying and injection method resulted in disease development. In contrast to this, Ashizawa et al (2011) were able to produce smut balls in panicles of different rice cultivars by injecting the conidial suspension at booting stage. Number of smut balls varied from 0.03 to 50.00 in field and from 0.10 to 25.00 in greenhouse conditions on 18 different cultivars. In the current study, number of smut balls varied from 0.63 to 5.35 in field and from 1.67 to 2.00 in greenhouse conditions. More spikelet sterility was noticed in rice plants of cultivar PR116 inoculated with syringe injection method followed by spray and dusting method. Similarly, Lore et al. (2013) also reported higher spikelet sterility in plants of rice cultivar PR116. Higher disease severity was produced in late transplanted crop as compared to timely transplanted. Similarly, Atia (2004) and Brooks et al. (2010) reported that early maturing rice genotypes escaped the false smut infec- 
tion, while the late maturing genotypes did not. However, coincidence of favourable weather conditions at the time of booting to flowering to stage of the crop had a great influence on the disease development as reported by Hegde et al. (2000).

Our results suggested that spray inoculation of cultured inoculum with artificially created humidity conditions produce more infected panicles $(51.12 \%)$ and number of smut balls per plant (7.33). Weather factors including high humidity $(88-90 \%)$, more rainfall $(25.3 \mathrm{~mm})$, lesser number of sunshine hours (6.7) during boot to flowering stage in rice plants have a great influence on disease development.

\section{REFERENCES}

Ashizawa, T., Takahashi, M., Moriwaki, J. and Kazuyuki, H. (2011). A refined inoculation method to evaluate false smut resistance in rice. J. Gen. Pl. Path., 77: 10-16.

Atia, M. M. M. (2004). Rice false smut (Ustilaginoidea virens) in Egypt. J. Pl. Dis. Prot., 111: 71-82.

Brooks, S. A., Anders, M. M. and Yeater, K. M. (2010). Effect of furrow irrigation on the severity of false smut in susceptible rice varieties. Pl. Dis., 94: 570-574.

Hegde, Y., Anahosur, K. H. and Kulkarni, S. (2000). Influence of weather parameters on the incidence of false smut of rice. Adv. Agric. Res. India, 14: 161-165.
Lore, J. S., Pannu, P. P. S., Jain, J., Hunjan, M. S., Kaur, R. and Mangat, G. S. (2013). Susceptibility of rice hybrids and inbred cultivars to false smut under field conditions. Indian Phytopath., 66: 397-399.

Nakamura, K., Izumiyama, N., Ohtsubo, K., Koiso, Y. and Iwasaki, S. (1994). "Lupinosis"- like lesions in mice caused by ustiloxin produced by Ustilagonoidea virens: A morphological study. Nat. Toxins, 2: 22-28.

Nessa, B., Salam, M. U., Haque, A. H. M. M., Biswas, J. K., Latif, M. A., Ali, M. A., Ansari, T. H., Ahmed, M., Parvin, N., Baki, M. Z. I., Islam, S., Islam, M. S. and Galloway, J. (2015). Rice false smut disease at different flowering times. Bangladesh Rice J. 19: 29-35.

Pannu, P. P. S., Thind, T. S. and Goswami, S. (2010). Standardization of technique for artificial creation of false smut of rice and its management. Indian Phytopath., 63: 234-235.

Raji, P., Sumiya, K. V., Renjisha, K., Dhanya, S. and Narayanankutty, M. C. (2016). Evaluation of fungicides against false smut of rice caused by Ustilaginoidea virens. Int. J. App. Nat. Sci. 5: 77-82.

Singh, I. (2009). Occurrence and Development of False Smut (Ustilaginoidea virens Cooke) of Rice. M.Sc. Thesis. Punjab Agricultural University, Ludhiana.

Wang, S., Li, M., Dong, H., Liu, X. Z., Ba, Y. J. and Yang, H. (2008). Sporulation, inoculation methods and pathogenecity of $U$. albicans, the cause of white rice false smut in China. J. Phytopath., 156: 755-757. 